\title{
SUMMARY OF A SURVEY OF ASTRONOMY LIBRARIES
}

Magda Vargha and Attila Mizser

Konkoly Observatory, Budapest

\begin{abstract}
A questionnaire about astronomy libraries was distributed in June 1988. The returns from 54 libraries are summarised; they show a large range in size, scope and procedures. Many libraries are connected to networks that give access to bibliographic databases, but only a small number use local computers for cataloguing. Some comments on the returns are given.
\end{abstract}

\section{INTRODUCTION}

A questionnaire on astronomy libraries was distributed in June 1988 with IAU Commission 5 Newsletter No. 3 in the hope that it would be possible to present a summary of the information at IAU Colloquium No. 110 on Library and Information Services on Astronomy. The initial response was insufficient, but further copies of the questionnaire were distributed at the Colloquium in Washington and at the IAU General Assembly in Baltimore in August. So far 54 returns have been received and so it seems worthwhile to summarise and comment on them. It is our hope that more librarians will respond and we will then prepare and distribute a full report on the survey.

The persons completing the questionnaires were asked to give qualifying remarks if the question or item was not appropriate to their situations. The questionnaire was as follows:

1. Name of organization and subdivision (if any) to which this questionnaire refers:

2. Is the library in one place or several? Where?

Approximate area: square metres

3. Is the library primarily for astronomy?

4. Approx number of books: Total: Before 1600: before 1900: Approx number of journals received: by purchase: by exchange: Approx number of books (excluding journals) purchased each year:

5. Number of library staff:

Approx number of users: Staff: Students: Other:

6. Do you allow your users open access to the shelves?

Do you allow your users to take (a) books and (b) journals away from the library?

7. Do you have significant use of microfilm or microfiche?

8. Do you keep a book catalogue on cards? or on computer?

9. Name of computer network (if any) to which library has access:

Name(s) of bibliographical database(s) used by the library:

10. Does the library have any special collections?

11. Is the library responsible for an archive of unpublished documents?

12. Is the library responsible for any photographic plates?

13. Is the library responsible for any publishing activities, such as production of newsletters?

14. Does the library (or other special group in the organisation) have any responsibility for the management of data held on magnetic tape?

15. Does the library (or other special group in the organisation) have any responsibility for management of data held on optical discs? 
2. SUMMARY OF ANSWERS

(1) The answers to the first item showed that:

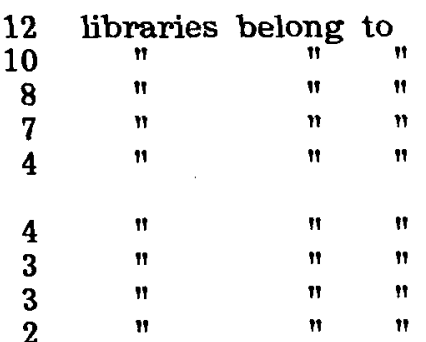

Observatories of Official Research Centers

University Observatories

University Research Institutes

Astronomical Faculties of Universities

Astronomical or Astrophysical Institutes of Official Research Centers

University Libraries

Observatories of Independent Research Centers

National Observatories

library is in a Private Observatory

Two questions arise: What are the best conditions for an astronomy library? What patron is considered as optimum for these libraries? One thing is certainly sure: for a library the most important condition is continuity, and the most difficult problem for a well-operating library is reorganization.

(2) Almost half of the 54 libraries are in two or more places. It is very natural if we think of the numerous mountain stations. But in some cases separation in several places is a direct consequence of reorganisation. About $30 \%$ of the libraries are in two places, and $17 \%$ are in three places. If a library operates in more than one place it must buy the most important books and journals in duplicate, thus causing some financial problems.

The areas of the libraries vary from 9 square metres to 2000 square metres. The average area is 260 square metres.

(3) Many branches of science are collected in the various astronomy libraries. Interest in computer sciences has grown rapidly; in the majority of libraries, however, primarily astronomical books are collected.

(4) The numerical data on the collections show a range in size from 400 to 88000 books and from 5 to 1000 in the number of journals obtained each year. It is very astonishing that the libraries - even the older ones - have very few old items, presumably because they had to part with the old ones for some reason. Nowadays a dangerous idea is flourishing in libraries. It says "The most valuable things can find better security in central places". It is not true at all. In the place where they are well-known and used sometimes, they surely have better conditions for preservation.

In almost all libraries there are many difficulties with the increase of the library stock. The most difficult problem is uncertainty. There were some very personal remarks regarding this problem on the questionnaires. The astronomical books are printed in relatively few copies; if one failed to order a book in time, it is very difficult to get it later. Not to mention the older astronomy journals! It is one of the most painful things in a library to stop ordering a journal that has been received for some decades by the library. The numerical data show that the exchange of publications among astronomy libraries is an important factor in developing collections.

(5) Comparing the numbers of users with the numbers of books and journals shows that in the astronomy libraries there are relatively big collections in proportion to the numbers of users. We think an astronomy library is in a very special situation among other libraries. Here most books and journals are used day after day (catalogs, textbooks, maps, etc.); the number of 
books and journals is not related to numbers of users as closely as in other libraries. There are many books that are essential for all astronomers. In an observatory almost all the astronomical staff use the library every day.

Similarly, it is seen that in comparison with the size of the collections very few persons work in these libraries. 1-2.5 librarians are working in 61\% of them, 3-9 librarians are working in $22 \%$ of the libraries, and $10 \%$ of the libraries have no librarians at all.

(6) In almost every library open access to the shelves is allowed for the users. In all libraries they also can take books away from the library. Only in two libraries (one of the two is the Konkoly Library) is it forbidden to take them outside the Institution. We think this rule is very useful. For example in our library there are many irreplaceable astronomical books that are the only copies in the country.

In 16 astronomy libraries the users cannot take away journals from the libraries. One librarian commented the answer "yes" with the remark "unfortunately". There is another remark: "It is not allowed but they do it unofficially".

(7) As far as microfiche and microfilms are concerned, they are used significantly in only 24 libraries.

(8) The library catalogs are kept mostly on cards. In 14 libraries the catalogs are also computerized. There is only one place where the catalogs are available only on computer. But there was a most interesting answer "on card: no; on computer: not yet".

(9) It is astonishing that, while over half of the libraries are connected to computer networks and to databases, only a few libraries have computerized their own catalogs. It is very probable that nowadays library collections are not the most important sources of information in the observatories. Information comes in various forms from outside. It can also be seen that there are so many data centers that it is not easy for a library to find the most suitable among them. It may cause us severe financial problems if we are not well informed in this business.

(10) There are various "Special Collections" in half of the libraries. We mention only some of them: "Slides", "Palomar Sky Survey", "Rare Books", "Old Journal Collections", "Papers of late astronomers", "Mathematical Tables", "Airy Rare Books", "Books of Professor Oort", etc.

(11) Among the 54 libraries only 20 libraries have archives. It would be very good to know what has happened to the old correspondences, architectural designs, drawings of the old instruments, old pictures of observatories, the portraits of the late astronomers, etc., where no archives exist. We do not know in how many institutions an archive exists other than as part of the library.

(12) We also cannot imagine what had happened to the older photographic plates. There are only 10 libraries in which the librarians are responsible for the photographic plates. It is very natural that current plates are situated in the rooms of the astronomers, or in a special laboratory. In our opinion it is very useful that the library should keep a catalog of them even if they are kept in another part of the observatory. 
(13) There are 12 institutions in which the libraries are responsible for publishing activities. In some cases these publications are connected with library work ("Library Guide", "Library News", "Acquisitions Lists" etc.) In 9 institutions the librarians aid in the distribution of reprint series.

(14) Significant databases on magnetic tapes are available in 22 libraries. The library has responsibility for these tapes in only 4 observatories. Most of these institutions have special computer centers where the tapes are kept. In some observatories the staff members have special collections on magnetic tapes. In some places the tapes are in the computer center, but are catalogued by the library.

(15) Optical discs are the means of the future in astronomy libraries. They are now used in only eight institutions, and there is only one library that is responsible for them. Within some years this situation will very probably change in the astronomy libraries.

\section{CONCLUDING COMMENTS}

Although the questionnaires returned to us so far represent only a small proportion of astronomy libraries, some very subjective remarks on the current situation in astronomy libraries in general are appropriate here.

We consider our time as a revolutionary period in our libraries. Within a few years we must use the new technical apparatus in all astronomy libraries. These new means will certainly change the traditional library life. Because astronomy libraries can only exist in close cooperation, it is also very important that these alterations should be going on in a coordinated way. We must give and receive new information by the same new means. That is why all astronomy libraries should be connected to some important central databases in the very near future, otherwise the exchange of information between these places would be only formal and not active and mutual.

The library - as these questionnaires also demonstrate - has manyfold tasks in an astronomical institution. Among them the most important is to provide current information for the astronomers. But a library is responsible not only for giving valuable information, but its task is also to preserve information by any means. To preserve every important result by the new means needs a new theoretical and technical concept. Our responsibility is to develop these new methods with the assistance of astronomers and computer experts. 